\title{
Investigation and Improvement of Strut-and-Tie Model for Design of End Anchorage Zone in Post-Tensioned Concrete Structure
}

\author{
Dong-Wei Hou \\ Assistant Professor, State Key Laboratory of Ocean Engineering and Collaborative \\ Innovation Center for Advanced Ship and Deep-Sea Exploration (CISSE), \\ Department of Civil Engineering, School of Naval Architecture, Ocean, and Civil \\ Engineering, Shanghai Jiao Tong University, 800 Dong Chuan Road, Minhang \\ District, Shanghai 200240, China
}

Jian-Li Zhao

Chief Engineer, Twentieth Construction Co. Ltd., China Metalurgy Inc.

Jack Shui-Long Shen*

Professor, State Key Laboratory of Ocean Engineering and Collaborative Innovation Center for Advanced Ship and Deep-Sea Exploration (CISSE), Department of Civil Engineering, School of Naval Architecture, Ocean, and Civil Engineering, Shanghai Jiao Tong University, 800 Dong Chuan Road, Minhang District, Shanghai 200240,

China

*Correspondence author

Tel: (86)21-3420-4301; Fax: (86)21-6419-1030; E-mail: slshen@ sjtu.edu.cn

\section{Jun Chen}

Lecturer, State Key Laboratory of Ocean Engineering and Collaborative Innovation Center for Advanced Ship and Deep-Sea Exploration (CISSE), Department of Civil Engineering, School of Naval Architecture, Ocean, and Civil Engineering, Shanghai Jiao Tong University, 800 Dong Chuan Road, Minhang District, Shanghai 200240,

China

Revised version to be resubmitted to

Construction and Building Materials

October 31, 2016 


\begin{abstract}
:
The strut-and-tie model (STM) is commonly used for the design of the end anchorage zone in post-tensioned concrete structures. In present work, the most accepted STMs in practice design for either centric or eccentric anchorage zone were inspected comprehensively based on experimental investigations and FEM simulations, to improve the models in accuracy, economy and efficiency. FEM was first employed to obtain the stress distribution in the anchorage zone, to reveal the influence of the anchor size and tension eccentricity on the compressive force, bursting force, spalling force and flexural tensile force. Based on FEM findings, the Mörsch STM for the design of centric end anchorage zone was configured and modified by taking into account the counteractive effect of the spiral circle and reinforcement on the distribution of stress in the anchorage zone. The adjusted Mörsch STM was employed for small eccentric end anchorage zone with the simplified equations from the FEM simulations. For the large eccentric end anchorage zone, a completely design procedure based on Schlaich model was offered by improving the determination method of the spalling force and bursting force in both values and locations. In above improvements on STMs, simplified equations were proposed for engineers to design the end anchorage zone more conveniently.
\end{abstract}

Keywords: Strut-and-Tie Model, Centric End Anchorage Zone, Eccentric End Anchorage Zone, Stress Redistribution. 


\section{Introduction}

Pre-stressing structures, especially post-tensioned concrete structures, are widely used in civil engineering [1-3], such as in bridge beams [4,5], high-rise buildings [1] and underground structures [6-8], due to the advantages of a low risk of cracking of the concrete matrix and the high tensile capacity of steel reinforcement [9-12]. In pre-stressed structures, the performance of the anchorage zone is critical for the safety and stability of the whole concrete structure [19-10].

The end anchorage has been the most commonly used both historically and in current practice [13-14]. For the end anchorage zone, including either centric or eccentric end anchorage zone, a local failure may occur in the immediate vicinity of the anchorage device if the local compression induced by the preload of the anchorage tendon exceeds the compressive capacity of the concrete matrix. To enhance the local strength, spiral reinforcement or steel twist wire mesh is usually employed in front of the bearing plate. Furthermore, cracks may also occur in the direction parallel to the axis of the pre-stressed tendon due to the lateral spreading of post-tension force. To prevent these cracks, transverse reinforcement is usually applied to resist the transverse tensile force in the concrete. Especially, for a large eccentric end anchorage zone additional reinforcement should be placed in the side away from the tendon path to resist the flexural-tensile force induced by the eccentric post-tension load.

In the past, the no-linear stress distribution within the anchorage zone has been investigated by elastic analysis [9-11], equilibrium methods of analysis [15-18], finite element method (FEM) [19-22], experimental investigations and Strut-and-Tie modeling [23,24]. Guyon [9-11] et al. proposed a simplified design method based on an elastic analytic solution for pre-stressing distribution within the anchorage zone under a 2-dimensional stress state, where spalling stress and bursting stress controlled the anchorage zone. The FEM offered a powerful tool to analyze the stress distribution in the anchorage zone. Generally, linear finite element analysis is used for the determination of un-cracked state stress, while nonlinear finite element studies can model the anchorage zone in a cracked state. To date, the most advanced method for the design of the anchorage zone in pre-stressed structures is the strut-and-tie model (STM) [19,20], in which approximate stress fields are used to formulate an equilibrium model consisting of compression struts and tension ties connected at discrete nodes. For the centric end-anchorage zone of steel reinforced structures, the most accepted STM is that proposed by Mörsch [25]. For an eccentric end-anchorage zone, an adjusted Mörsch STM is usually used to adapt the small eccentric post-tension condition. For the large eccentric end anchorage zone, a design method proposed by Schlaich $[23,24]$ and suggested by the International Federation for Pre-stressing (FIP), is most applied. Although some new methods to generate an optimal STM [26, 27], and combined method of experimental investigations and non-linear FEM simulations to study shear and bending 
performances of complex concrete components [28, 29], have been developed in recent years, the traditional STMs are still the most convenience and effective method in practical design for pre-stressing structures [30-32]. Today, a typical STM method, usually combined with the linear FEM analysis on the stress distribution in a sound and unreinforced end-anchorage zone, is usually conducted as shown in a flow-chart format in figure 1.

In present work, the most accepted STMs in practice for the design of end anchorage zone were inspect comprehensively based on FEM simulations and experimental investigations, to refine the models in accuracy, economy and efficiency. FEM was first employed to obtain the force flow through the anchorage zone, following by the configuration of the STM with the Mörsch model for centric end anchorage zone, the adjusted Mörsch model for small eccentric end anchorage zone, and the Schlaich method for large eccentric end anchorage zone. To verify the Mörsch model, a steel reinforced concrete specimen designed from the STM is tested to observe if the predict failure load fits the test results well and if all the reinforcements achieve yielding when the specimens failed. As a result, the counteractive effect of the spiral circle and reinforcement was observed and taken into account in the improved Mörsch STM. Then, the STM for small eccentric end anchorage zone was adjusted based on the improved Mörsch model, and a modification to Schlaich model for large eccentric end anchorage zone was suggested based on the findings of FEM simulations.

\section{FEM Analysis}

\subsection{FEM Model}

The FEM analysis is performed on the end-anchorage zone of a pre-stressing concrete member under centric loading in an elastic plane stress condition [33]. The software 'ANSYS10.0' [34] is employed to simulate. In the FEM model, the equivalent compressive load acting on the anchor plate is applied instead of the post-tension load acting on the anchorage tendon, which was suggested by Burdet [33] and Sanders [35], and accepted in present work. Figure 2 shows the 2-Dimensional model (Fig.2(a)) and mesh (Fig.2(b)) of FEM for the centric end-anchorage zone, and Table 1 lists the related parameters in FEM simulations. The length of the FEM model is set as 2 times of the lateral dimension $(2 h)$, which is sufficient to represent the whole anchorage zone, as the below FEM results demonstrate that the stress distribution near the bottom boundary is affected little by anchorage (see Fig. 3 5 and Fig.9). In the FEM model, the concentrated load acting on the anchor plate is substituted by an equivalent uniform load applied on the top surface of the concrete member, which produces little difference in stress distribution within the vicinity of concrete top surface due to a high stiffness of the anchor plate [32, 33]. To achieve the maximum bursting stress, the bottom of the FEM model is fixed only in the vertical direction, 
allowing swelling and deformation to occur in the lateral direction. The FEM model is meshed using isoparametric elements with 4-nodes (the "PLANE42" element) [34].

The ratio of the anchor size to the lateral dimension of the concrete member, $a / h$, governs the distribution of stresses in the anchorage zone, through which a lateral spreading of the post-tension force occurs at some distance in front of the anchorage device. Therefore, FEM samples with various $a / h$ values ranging from $0.1 h$ to $0.8 h$ are examined for the centric end anchorage zone.

Regarding the eccentric end anchorage zone, the FEM models are similar to those for the centric end anchorage zone, except the load locations. The anchorage eccentricity defined by $e / h$, where $e$ is the offset distance of the pre-load from the central line of the member, as well as the anchor size ratio $a / h$, are investigated as the key parameters affecting the distribution of stresses in the eccentric end anchorage zone. FEM simulations with various combinations of $a / h$ and $e / h$ (subjecting to $a / h+2 e / h \leq 1$ ) shown in table 2 are carried out for the eccentric end anchorage zone.

\subsection{FEM Results}

\subsubsection{Centric End Anchorage Zone}

\section{(1) Stress Distribution}

Fig. 3 shows the distribution and flow of the principal stresses in the centric end anchorage zone with $a=0.4 h$, typically. A similar law can be observed in other cases with $a / h$ varying from 0.1 to 0.8 . The compression initiates from the anchor plate and is transferred to the rest of the anchorage zone after a lateral spread within a particular range of dispersion angle for a distance in front of the anchor plate. The major principal stress, which is tensile stress and of greatest interest here, distribute in the anchorage zone symmetrically along the central axis. The tensile stress in $x$ direction (perpendicular to the tendon path) in front of the anchor plate is the bursting stress, which is caused by the lateral spreading of the tendon force from the anchor plate to the entire anchorage zone. The tensile stress acting parallel to the surface of the concrete around the two corners near the anchor plate is the spalling stress, mainly caused by the compatibility conditions of concrete displacements.

\section{(2) Compressive Stress}

Fig.4 shows the distribution of the compressive stress along the tendon path at every $a / h$ value, where concentration of compression in the vicinity of the anchor plate are observed obviously. With increase of $a / h$, the compression concentration becomes weak, until a nearly uniform stress $\sigma_{0}=P / A$ acts in the whole anchorage zone at $a / h=1$. For each $a / h$, the compressive stress decreases with the distance from the anchor plate, and approaches the uniform stress at a sufficient distance away from the anchor plate, which also demonstrates that the length of FEM 
model is sufficient to represent the whole anchorage zone.

\section{(3) Bursting Stress}

Fig.5 shows the distribution of the bursting stress along the tendon path at every $a / h$ value, where a normalized stress $\sigma_{\text {burst }} / \sigma_{0}$ (where $\sigma_{0}$ is the mean stress in the tendon path, $\sigma_{0}=P / A$ ) and a normalized distance from the anchor plate $y / h$ are employed to make the analysis more general by non-dimensional parameters. For each $a / h$, the bursting stress along the tendon path initiates from a special distance from the anchor plate and increases rapidly with the maximum achieved at a farther distance, following by approaching zero at a sufficient distance of about $1.5 h$. With increase of $a / h$, the initiation distance of the bursting stress increases, and the maximum value of the bursting stress decreases, as well as the bursting force described by the figure area enclosed by the bursting stress curve with the $x$-axis. When the $a / h$ is 1 , which means the size of the anchor plate is the same with the member section, bursting force disappears and only compression in the $y$ direction acts in the anchorage zone. A nearly linear relationship between the maximum bursting stress or maximum bursting force and the size ratio of anchor $a / h$ is observed, as shown in Fig. 6.

A comparison of bursting stress along the tendon path with other researches $[11,17,18,23$, 33] is conducted and shown in Fig.7, suggesting that the FEM results obtained based on the FEM models and parameters used in present work are close to Guyon's theoretical solution [11].

\section{(4) Spalling Stress}

The maximum spalling stress acting parallel to the top surface of the specimen decreases with the size ratio of anchor $a / h$ from about $0.57 \sigma_{0}$ at $a / h=0$ to 0 at $a / h=1$. Since the spalling stress are mainly caused by the compatibility conditions of concrete displacements, which occurs only within a small region in a size usually less than $h / 20$, the spalling force resultant by the spalling stress is usually small [11].

\subsubsection{Eccentric End Anchorage Zone}

\section{(1) Stress Distribution}

In eccentric end anchorage zone, stresses arising in the two sides of the concrete member can be calculated simply by the following equation [36]:

$$
\sigma_{1,2}=\frac{P}{b h}+\frac{M}{W}=\sigma_{0}\left(1 \pm 6 \frac{e}{h}\right)
$$

where, $M$ is the additional bending moment, $M=P \times e ; W$ is the moment of section of anchorage zone, $W=\left(b \times h^{2}\right) / 6$. From equation (1), the eccentricity $e / h=1 / 6$ is obtained as the divide of large end anchorage zone (when $e / h>1 / 6$ ) from small end anchorage zone (when $e / h \leq 1 / 6$ ), which are distinguished according to whether tensile stress arises in the side away from the tendon path in the concrete member.

Fig.8 illustrates the distribution of the maximum principle stress under a small eccentric condition with $e / h=0.15$ and $a / h=0.3$ in the left panel (Fig.8a), and a large eccentric condition with 
$e / h=0.3$ and $a / h=0.3$ in the right panel (Fig.8b), respectively. For the small eccentric anchorage zone, the bursting stress appears in front of the anchor due to the lateral spreading of the tendon load, while the spalling stress arises near and parallel to the surfaces around the two corners neighboring the anchor plate. For the large eccentric end anchorage zone, the bursting force acts within a smaller region in front of the anchor plate than that in the small eccentric anchorage condition. Meanwhile, the spalling stress acting in the side away from the tendon path turns into a flexural-tensile stress $\left(\sigma_{\mathrm{FT}}\right)$ across the entire vertical section of the anchorage zone due to the additional bending moment induced by the eccentric load.

\section{(2) Bursting stress}

Fig.9 illustrates the bursting stress (normalized by $\sigma_{\text {burst }} / \sigma_{0}$ ) along the tendon path against the distance (normalized by $y / h$ ) from the anchor plate with the eccentricity $e / h$ ranging from 0 to 0.4 at $a / h=0.2$. The initiation distance of the bursting stress from the anchor plate decreases with $e / h$. However, the maximum bursting stress increases with $e / h$ except $e / h=0.4$, for which the anchor plate reaches the edge of the top surface of the concrete member, reducing the spreading of the tendon force due to the limitation of the member size.

Furthermore, the variation of the maximum bursting stress with the eccentricity $e / h$ behaves different for different size ratio of anchor $a / h$, as shown in Fig.10. The maximum bursting stress $(e / h>1 / 6)$, the maximum bursting stress increases dramatically with $e / h$ for $a / h<0.2$ and decrease obviously with $e / h$ for $a / h \geq 0.2$, respectively, implying that increasing the size ratio of anchor $a / h$ can increase the safety significantly for large eccentric pre-stressing members.

The bursting force in both value and location can be obtained by integrating the bursting stress along the tendon path. For each $a / h$, the bursting force against $e / h$ are shown in Fig.11 (a), indicating that the bursting force changes little with $e / h$ in the small eccentric condition $(e / h \leq 1 / 6)$, but decreases obviously with $e / h$ in the large eccentric condition $(e / h>1 / 6)$. For the same eccentricity $e / h$, the bursting force decreases with $a / h$, behaving a similar trend found in the centric end anchorage zone as shown in figure 5. As for the location of the bursting force, the distance of the bursting force acting point from the anchor plate, which is normalize by $d / h$ in figure 11 (b), decreases with $e / h$ for each $a / h$ (especially for $e / h>1 / 6$ ), but increases with $a / h$ for each eccentricity $e / h$ (especially for $e / h \leq 1 / 6$ ).

Guyon $[10,11]$ once suggested a method to estimate the bursting force in the eccentric end anchorage zone by assuming that the bursting force only occurs in a prism that is symmetrical around the tendon path, with $a_{2}=h-2 e$ in lateral dimension and $1.5 \sim 2 a_{2}$ in height. Besides the theoretical solution, a simplified equation was suggested as follows:

$$
T_{\text {burst }}=0.25 \times P \times\left(1-a / a_{2}\right)
$$


Where $a_{2}$ is 2 times the distance of the tendon path from the nearby boundary. From Fig.12, it is observed that the simplified equation agrees with FEM simulations better than Guyon's $\underline{\text { theoretical solution, which underestimates the bursting force in most cases for different } a / a_{2}}$. Therefore, equation (2) is simple but accurate enough for calculation of the bursting force in the eccentric end anchorage zone.

Similarly, a simple equation to determine the distance of the bursting force center from the anchor plate, $d$, can be obtained based on above FEM results as follows:

$$
d=\frac{1}{3}(a-2 e)+0.46 h
$$

\section{(3) Spalling Force}

The spalling stress mainly occurs in the side away from the tendon path and near the top surface of the concrete (Fig. 8), leading to a stripping of the concrete cover when the member fails. The spalling force is determined by the maximum value among the integrals of the spalling stress over a series of paths parallel to the tendon line within the spalling stress area. FEM results show that the spalling force is less affected by $a / h$ (within an error less than $3 \%$ ). Fig.13 illustrates the spalling force against $e / h$, where the spalling force changes little with $e / h$ for the cases of small eccentric anchorage, but increases obviously with $e / h$ for the cases of large eccentric anchorage. Guyon once suggested an approximate equation to estimate the spalling force by

$$
\frac{T_{\text {spall }}}{P}=0.04+0.16 \times\left(\frac{e}{h}\right)^{3}
$$

However, it overestimates the spalling force compared to the FEM simulations, as shown in Fig.13. Especially, this equation gives too conservative results for the small eccentric condition.

\section{(4) Flexural Tensile Stress}

For a large eccentric end anchorage zone with $e / h>1 / 6$, the eccentricity of the tendon load produces flexural tensile stress in the region closing to the boundary away from the anchor path. FEM simulations show that the flexural tensile stress (or flexural tensile force) is little affected by $a / h$, usually with a small error less than $1 \%$. The flexural tensile stress or flexural tensile force can be obtained by FEM results or by the following equations in terms of $e / h[36]$ :

$$
\begin{gathered}
\sigma_{\mathrm{FT}-\mathrm{max}}=\sigma_{1}=\sigma_{0}\left(6 \frac{e}{h}-1\right) \\
T_{\mathrm{FT}}=\frac{P}{24} \times \frac{\left(6 \frac{e}{h}-1\right)^{2}}{\frac{e}{h}}
\end{gathered}
$$

For $e / h=0.5$, it is difficult to achieve in practice due to the size limitation of the anchor plate relative to the dimension of the concrete member, so $e / h=0.5$ is the upper limit eccentricity for the flexural tensile force. Meanwhile, $e / h=1 / 6$ is the lower limit as the flexural tensile force does not 
occur in small eccentric end anchorage zone.

\section{STM and Improvement}

\subsection{Mörsch STM for Centric End Anchorage Zone}

Based on the principal stress flow in the centric end-anchorage zone obtained from the FEM analysis, a preliminary STM configuration can be determined as described by Mörsch [25], where ties subjecting to tension connect with struts subjecting to compression with discrete nodes. To refine the Mörsch STM, it is important to determine firstly the location of the ties resisting the bursting force. Generally, the ties should be placed consistent with the bursting force center, which is calculated by integrating the bursting stress over the entire tendon path, to obtain the best reinforcement performance of the anchorage zone [23, 37]. However, if no FEM simulations, it is more convenient in practice design to determine the bursting force center by introducing a parameter, disperse angle $\beta$, defined by the angle between the tendon line and the connecting line from the anchor plate center to the quarter point of the lateral section containing the bursting force center, as illustrated in Fig.14 (a). Based on FEM simulations, the distance of the bursting force center from the anchorage plate, $d$, is determined for each $a / h$, and the disperse angle $\beta$ can be calculated by $\tan \beta=h /(4 d)$. Fig.14 (b) shows that $\beta$ decreases with $a / h$ ranging from 0 to 1 . To simplify the calculation in practice design without FEM simulations, the disperse angle is suggested to calculate by the following fitting equation in terms of $a / h$ (with the correlation coefficient $R^{2}=0.99$ ):

$$
\beta\left({ }^{\circ}\right)=19\left(\frac{a}{h}\right)^{2}-27\left(\frac{a}{h}\right)+28
$$

In general, $\beta$ can also be taken as $26.5^{\circ}$ to estimate the location of bursting force center approximately, which leads to an acceptable deviation from the FEM results and keeps the results on the conservation side in most cases. However, for $a / h<0.1, \beta$ should be calculated from equation (7). After knowing $\beta$, the bursting force location $d$ can be obtained by $d=h /(4 \tan \beta)$.

After the Mörsch STM is configured as shown in Fig.15 (a), the internal force of each strut and tie can be computed using the equilibrium of forces and moments at every node, which is responsible for the determination of the reinforcement ratio and configuration. The pre-load $P$ is substituted by two components, $P_{1}$ and $P_{2}$, acting symmetrically on the quarter points of the

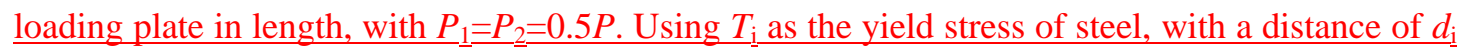
from the top surface of the concrete specimen, the distance of the reinforcement centroid from the top surface, $d$, can be calculated by:

$$
d=\sum_{i=1}^{n} T_{i} d_{i} / \sum_{i=1}^{n} T_{i}
$$


centre line, the load $P$ can be obtained from the equilibrium of the moment relative to the action point of $P_{1}$ (or $P_{2}$ ) as follows:

$$
P=\frac{8 d}{h-a} \sum_{i=1}^{n} T_{i}
$$

Based on equation (8) and (9), parameters of the reinforcement configuration were determined (Fig. 15(a)) to subject an ultimate failure load $288 \mathrm{kN}$, assuming reinforcement achieves the yielding point of steel.

A problem should be noted that the STM by Mörsch is designed based on the elastic FEM analysis, without taking into account the changes in stress distribution induced by the presence of the added reinforcements. Actually, the spiral for enhancing the local compressive strength under the anchor plate, and the stirrups and longitudinal reinforcing bars resisting the tension stress well lead to a redistribution of stress in the pre-stressing concrete member. To verify the Mörsch STM, experimental studies were carried out [34], where a C40 concrete specimen of $500 \mathrm{~mm}$ (width) $\times 200 \mathrm{~mm}$ (thickness) $\times 750 \mathrm{~mm}$ (length) in size (Fig.16(a)) was tested. Results show that all $\underline{\text { the reinforcements reach yielding when the specimen failed (Fig.16(b)). However, the test }}$ ultimate load of the specimen is $320 \mathrm{kN}$, which is higher than the predicted value $288 \mathrm{kN}$ by $11.1 \%$. From the crack distribution in failed specimen (Fig.17), a pyramid or cone shaped area of concrete, of about half the size of the anchor plate $(a / 2)$ in height, is observed under the anchor plate. This phenomenon was also found by Sanders [35] and Taylor [38]. The pyramid shaped concrete reveals that the uniform compressive load from the anchor plate is transferred downwards for a certain distance, $l$, away from the loading plate, before it spreads into a wider range of the lower region within the range of a particular dispersion angle. Here, the transferring of the compressive load in the vertical direction is induced by the presence of the spiral reinforcement, as this prevents the load from dispersing sideways directly from the top surface of the specimen, and extends the distance over which the load begins to disperse.

According to the experimental results and previous research by Sanders [34], $l$ is suggested to be a/4. Correspondingly, a modification to Mörsch's STM can be performed by translating the whole strut-and-tie system without any changes in STM configurations downwards for a distance of a/4. The modified Mörsch STM is shown in Fig.15 (b). Using the modified model, the predicted ultimate load is $326.6 \mathrm{kN}$, with an small error of about $2 \%$ compared with the test failure load. Therefore, the modification is appropriate for Mörsch's STM, because it takes into account the effect of the spiral reinforcement on the stress distribution in the end anchorage zone.

\subsection{STM for Eccentric End Anchorage Zone}

\subsubsection{Small Eccentric End Anchorage Zone}

Compared with the centric end anchorage zone, no new type of failure modes occur in the 
small eccentric end anchorage zone, except the difference in the stress distribution. Therefore, the STM for small eccentric end anchorage zone can be designed following the Mörsch's STM by adjusting the configuration of ties and struts.

For a small eccentric end anchorage zone, the counteractive compressive stress linearly but non-uniformly distributed on the bottom of the anchorage zone, $\sigma_{1}$ and $\sigma_{2}$ (Fig.18b), are calculated by equation (1). Correspondingly, the counter compressive forces $C_{1}$ and $C_{2}$ both in values and locations are obtained by integrating the compressive stress over the area in the left and right side of the tendon line respectively. The vertical struts are placed to resist the compressive force by meeting the location of $C_{1}$ or $C_{2}$. The bursting force is determined by equation (2) for its value and equation (3) for its location, respectively. The final configuration of the STM for small eccentric end anchorage zone is shown in Fig.18 (b). To consider the effect of the spiral on the redistribution of the compressive stress in front of the anchor plate, the STM configuration is moved downward by $a / 4$ just like the situation in the centric end anchorage zone. At last, the internal force in every tie and strut in the STM is calculated by the equilibrium principles in force and moment for every node, which is responsible for the determination of the reinforcement ratio and locations.

\subsubsection{Large Eeccentric End Anchorage Zone}

For the large eccentric end anchorage zone, Schlaich [23, 24] proposed a method for configuration of the STM based on FEM analysis together with the load transfer path method as illustrated in figure 19.

(1) The counteractive stress in the vertical direction acting on the bottom of the anchorage zone are summarized into four forces, the tensile force $T_{1}$ and the compression forces $C_{1}, C_{2}, C_{3}$, by integrating the stress over a certain part of the bottom area in their values and locations (Fig.19(a)). Here, $T_{1}$ is the integral of the tensile stress on the bottom, while $C_{1}$ is set to balance $T_{1}$, forming a closed load transfer path like a " $U$ " shape with $T_{1}$ and keeping equilibrium in force in this local zone away from the tendon path. $C_{2}$ and $C_{3}$ acting on the left and right side of the tendon path respectively subject to the compressive load $P$ collectively, with $C_{2}=P_{1}$ and $C_{3}=P_{2}$, where $P_{1}$ and $P_{2}$ are the two components of the compressive load $P$.

(2) Based on FEM simulations, the forces in the lateral direction, such as the tension force $T_{2}$ and the compressive force $C_{4}$ acting on section $\mathrm{CD}$, and the tension force $T_{3}$ on section $\mathrm{AB}$, are determined in both values and locations by integrating the stresses arising in these sections (Fig.19 (b)).

(3) According to the transfer paths of the tensile forces and compressive forces, a preliminary STM is configured as shown in figure 19 (c). The vertical struts resisting $C_{1}, C_{2}$ and $C_{3}$ and the vertical tie resisting $T_{1}$ are determined firstly. Then, the lateral strut resisting $C_{4}$ and the lateral tie resisting $T_{2}$, which arise where the force flow turns its transfer path, are determined as well. The 
locations of the ties and struts are consistent with the locations of their corresponding forces. Finally, the STM configuration is completed with essential incline ties and struts supplemented to enhance the robust of the joints.

The configuration procedure of STM for large eccentric end anchorage zone by Schlaich is widely applied due to its strong theory base and simplification to handle. However, the location of section $\mathrm{CD}$, which is necessary for determination of $T_{2}$ and $C_{4}$, is difficult to find, because many tries are required to select the best location of section $\mathrm{CD}$ where $T_{2}$ reaches the maximum among all the possible section locations from the anchor line to the member boundary. To solve this problem, FIP suggested an approximate method by making $T_{2}=T_{1}$, which means the angle of the incline strut connecting $T_{2}$ (or $T_{1}$ ) and $C_{4}$ (or $C_{1}$ ) against the vertical boundary of the anchorage zone, $\alpha$, equals to $45^{\circ}$. Then, the compressive strut $C_{4}$ in its value and location is also determined. However, FEM results reveal that the spalling force $\left(T_{2}\right)$ is very different from the flexural tensile force $\left(T_{1}\right)$ though they are in the same order of magnitudes, as shown in Fig. 20(a). Therefore, the FIP suggested method offers only a rough approximation in most cases for the large eccentric end anchorage zone. To refine the STM, a more accurate method to determine the relationship between $T_{1}$ and $T_{2}$ is proposed here. From Fig.20(b), $T_{2}$ can be expressed by a linear equation with $T_{1}$ as following:

$$
T_{2}=0.7243 \times T_{1}
$$

where, the correlationship coeficient $\mathrm{R}^{2}=0.9577$. As $T_{2}=T_{1} \times \tan \alpha$, $\alpha$ is obtained to be $\pi / 5$. It is observed from Fig.20 (b) that taking $\alpha$ to be $\pi / 5$ is applicable for most cases of $e / h$ for the large end anchorage zone. Considering $T_{2}=0.03 P$ for the situation $0.167 \leq e / h<0.25$, the spalling force can be discribed completely as following:

$$
T_{2}= \begin{cases}0.03 P & \text { for } 0.167<e / h<0.25 \\ T_{1} \times \tan \frac{\pi}{5} & \text { for } 0.25 \leq e / h<0.5\end{cases}
$$

When $T_{2}$ is obtained, $\alpha$ can be used to locate the incline strut $\mathrm{AB}$ and calculate the internal force in $\mathrm{AB}$. From the equilibrium of the left part of the configuration in $x$ direction, $C_{4}=T_{2}$ is obtained.

The bursting force carried by tie EF is also determined by equation (2). The location of strut EF can be calculated as shown in Fig. 21 (b), which is the magnified graph of the local zone under the anchor plate. An auxiliary line perpendicular to line EF is drawn from point $\mathrm{G}$ to point $\mathrm{M}$. According to the geometric relationship in $\triangle \mathrm{GMF}$ and the equilibrium of point $\mathrm{G}$, we can obtain

$$
\tan \angle \mathrm{MGF}=\frac{\mathrm{MF}}{\mathrm{GM}}=\frac{T_{3}}{C_{3}}
$$

Therefore,

$$
\mathrm{GM}=\mathrm{MF} \times \frac{C_{3}}{T_{3}}
$$


As $\mathrm{MF}=l_{1}-0.25 a$, where $l_{1}$ can be obtained from $C_{3}$, the location of strut $\mathrm{EF}$ is finally determined from equation (13). At last, the internal forces in other ties and struts can be calculated by the equilibrium of every node, and the STM configuration is completed. The reasonability of this configuration process for large eccentric end anchorage zone depends on the fact that it can be transformed into the configuration method for small eccentric end anchorage zone when $e / h \leqslant 1 / 6$ (section 3.2.1). Of course, this design method should be verified by experimental tests in further $\underline{\text { studies. }}$

In addition, although the counteractive effect of the spiral circle and reinforcement on stress distributions is taken into account for modification of both centric and eccentric end anchorage zone, it requires further studies by experimental investigations and non-linear FEM simulations in further studies.

\section{Conclusion}

In present work, the most accepted STMs in practice design for either centric or eccentric anchorage zone were inspected comprehensively based on experimental investigations and FEM simulations, to improve the models in accuracy, economy and efficiency. Following conclusions can be derived as follows:

(1) The linear FEM is effective for determination of the force flow or principal stress vectors in a pre-stressed member, assuming the FEM model to be isotropic and homogeneous. Based on the FEM results, the STM can be configured with the Mörsch model for the centric end anchorage zone. However, the redistribution of stresses induced by the counteractive effect of the reinforcements, particularly the spiral reinforcement, should be taken into account by moving the STM configuration downward for a distance $a / 4$ in the design of the end anchorage zone.

(2) In small eccentric condition, the adjusted Mörsch STM is applicable for design of the end anchorage zone with the simplified equations from FEM simulations to determine the bursting force for both values and locations.

(3) For large eccentric end anchorage zone, as a modification of the FIP suggested method from the Schlaich model, the spalling force can be estimated through a linear relationship with the flexural tensile force by $T_{2}=T_{1} \times \tan (\pi / 5)$ for most cases of eccentricity. The modified STM configuration method is more accurate but easy to handle for civil engineers to design the end anchorage zone in large eccentric pre-stressing concrete structures.

\section{Acknowledgments}

The research work described herein was funded by the National Science Foundation of China (Grant No. 51308334) and the National Basic Research Program of China (973 Program: 


\section{References}

[1] Leonhardt F. Prestressed concrete design and construction. Berlin: Wilhelm Emst \& Sohn; 1964.

[2] Breen JE, Burdet OL, Roberts CL. Anchorage zone reinforcement for post-tensioned concrete girders. NCHRP reports no. 356; 1994.

[3] Podolny WJ. The cause of cracking in post-tensioned concrete box girder bridges and retrofit procedures. PCI J 1985; 30(2):82-139.

[4] Yang J, Teng JG, Chen JF. Interfacial stresses in soffit-plated reinforced concrete beams. Proc Inst Civil Eng - Struct Build 2004; 157(1):77-89.

[5] Kim DJ, Lee JB, Lee, YH. Effectiveness factor of strut-and-tie model for concrete deep beams reinforced with FRP rebars. Composites: Part B 56 (2014) 117-125.

[6] Wu HN, Shen SL, Liao SM, and Yin ZY. Longitudinal structural modelling of shield tunnels considering shearing dislocation between segmental rings, Tunneling and Underground Space Technology, 50(2015), 317-323.

[7] Yu N, Bai TH, Zhu HH. Model experimental study on joints stiff of precast and prestressed concrete lining in shield tunnels. Chin J Undergr Space Eng 2009, 5(3):439-49.

[8] Liao SM, Peng FL, Shen SL. Analysis of shearing effect on tunnel induced by load transfer along longitudinal direction. Tunneling Undergr Space Technol 2008; 23(4):421-30.

[9] Guyon Y. Contraintes dans les pièces prismatiques soumises à des forces appliqués sur leurs bases, auviosinage de ces bases. International Association for Bridge and Structural Engineering, 1961, 11: 165-226.

[10] Guyon Y. Limit-state design of prestressed concrete, vol. 2, the design of the member. John Willey \& Sons, New York, 1974.

[11] Guyon Y. Prestressed concrete. John Willey \& Sons, New York, 1953.

[12] Shen SL, Cui QL, Ho EC, Xu YS. Ground response to multiple parallel microtunneling operations in cemented silty clay and sand, Journal of Geotechnical and Geoenvironmental Engineering, 2016, 142(5), 04016001(1-11).

[13] Shen SL, Wu HN, Cui YJ, and Yin ZY. Long-term settlement behavior of the metro tunnel in Shanghai, Tunneling and Underground Space Technology, 40(2014), 309-323.

[14] Wu HN, Shen SL, Chai JC, Zhang DM, and Xu YS. Evaluation of the train-load-induced settlement of metro tunnels in Shanghai, Geotechnical Engineering, ICE Proceedings, 2015, 168(5), 396-409.

[15] Gergely P., Sozen M.A. Design of anchorage-zone reinforcement in prestressed concrete beams. PCI Journal, 1967, 12(2): 63-75.

[16] Gergely P., Sozen M.A., Siess C.P. The effect of reinforcement on anchorage zone cracks in prestressed concrete members. Research Series No. 271, University of Illinois Civil Engineering Structural, 1963.

[17] Magnel G. Prestressed concrete. McGraw Hill, New York, 1954.

[18] Lenschow R., Sozen M.A. Practical analysis of the anchorage zone problem in prestressed beams. ACI Journal, 1965, 62(11): 1421-1437. 
404

[19] Egeberg J.L. A finite element investigation of the anchorage zone of prestressed concrete beams. Series Report No. 363, University of California, 1968.

[20] Adeghe L.N., Collins M.P. A finite element model for studying reinforced concrete detailing problems. Publ. No. 86-12, Department of Civil Engineering, University of Toronto, 1986: 66-74

[21] Park JW, Yindeesuk S, Tjhin T, Kuchma D. Automated Finite-Element-Based Validation of Structures Designed by the Strut-and-Tie Method. J. Struct. Eng. 2010.136:203-210.

[22] Oehlers D.J. Longitudinal splitting in the anchorage zones of post-tensioned members. Magazine of Concrete Research, 1997, 49(180): 173-183.

[23] Schlaich J., Schäfer K., Jennewein M. Toward a consistent design of reinforced and prestressed concrete structures. PCI Journal, 1987, 32(3): 74-151.

[24] Schlaich J., Schäfer K. Design and detailing using strut-and-tie models. Structure Engineer, 1991, 69(6): 113-125.

[25] Mörsch E. Concrete-Steel Construction. New York: McGraw Hill; 1909 (English Translation by E. P. Goodrich) pp 368.

[26] Liang Q. Q., Xie, Y. M. and Steven, G. P. Generating optimal strut-and-tie models in prestressed concrete beams by performance-based optimization, ACI Structural Journal, 2001, 98(2), 226-232.

[27] Liang, Q. Q., Xie, Y. M. and Steven, G. P.. Topology optimization of strut-and-tie models in reinforced concrete structures using an evolutionary procedure. ACI Structural Journal, 2000, 97(2), 322-332.

[28] Maher A, Adam, Mohamed Said, Ahmed A. Mahmoud, Ali S. Shanour. Analytical and experimental flexural behavior of concrete beams reinforced with glass fiber reinforced polymers bars. Construction and Building Materials 84 (2015) 354-366.

[29] Maher A. Adam, Mohamed Said, Tamer. M. Elrakib. Shear performance of fiber reinforced self compacting concrete deep beams. International Journal of Civil Engineering and Technology, 2016, 7(1):25-46.

[30] Zhao JL, Shen SL, Wang LB, Chen J. A Design Approach for the Interior Anchorage Zone of Post-tensioned Concrete Structure. KSCE Journal of Civil Engineering (2011) 15(3):487-495.

[31] Shen SL, Hou DW, Zhao JL, Horpibulsuk S, Yin ZY. Assessment of internal forces for intermediate anchorage zone of post-tensioned concrete structure. Construction and Building Materials 64 (2014) 370-378.

[32] Zhao JL, Shen SL, Sun Y. Application of Strut-and-Tie Model for Design of Interior Anchorage Zone in Post-tensioned Concrete Structure. J. Shanghai Jiaotong Univ. (Sci.), 2010, 15(3): 273-278.

[33] Burdet OL. Analysis and design of anchorage zones in post-tensioned concrete bridges. PhD Dissertation, University of Texas at Austin, Austin, USA, 1990.

[34] ANSYS Inc. (2006). ANSYS release 10.0 - User's manual, Pennsylvanian, American.

[35] Sanders DH. Design and behavior of post-tensioned concrete anchorage zones. PhD Dissertation, University of Texas at Austin, Austin, USA, 1990.

[36] Lin TY, Burns NH, Design of prestressed concrete structures (third edition). Wiley, New York, NY. 1981.

[37] Zhao JL. Strut-and-Tie model for anchorage zone of prestressed concrete structures with its application, Ph.D dissertation, Shanghai Jiao Tong University, Shanghai, China, 2010.

[38] Taylor SJ. A three dimensional stress distribution problem in the anchorage zone of a post-tensioned concrete beam. Magazine of Concrete Research, 1967, 19(58): 54-57. 


\section{Figures, Tables and Notation List}

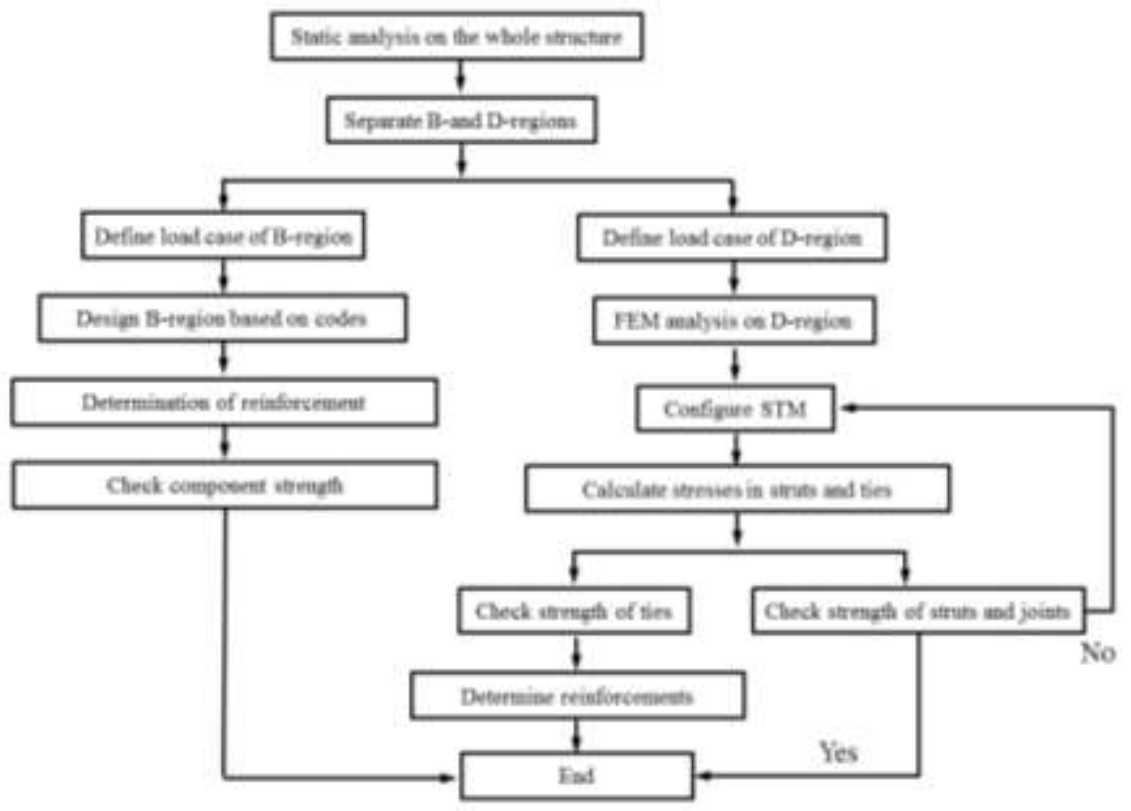

Fig.1 Design procedure for end anchorage zone with STM

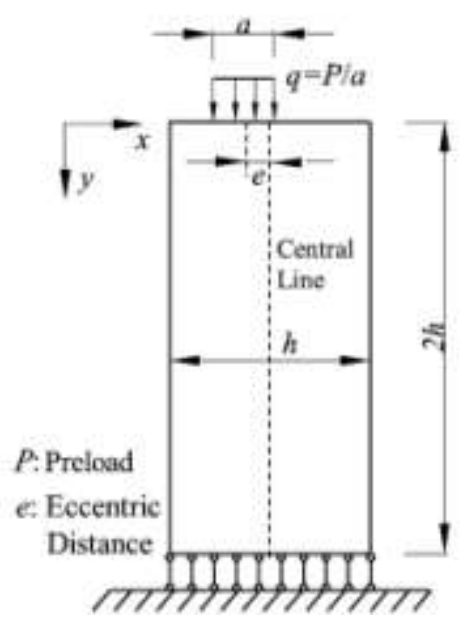

(a)

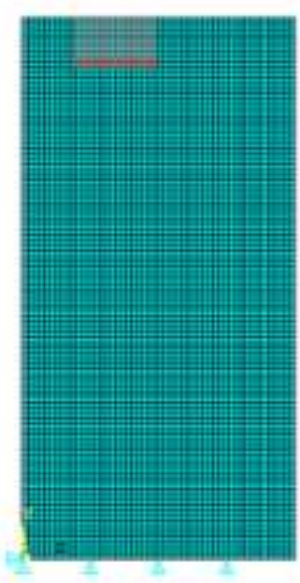

(b)

Fig. 2 Finite element model (a) and mesh of FEM (b) for end anchorage zone in 2-dimensions 


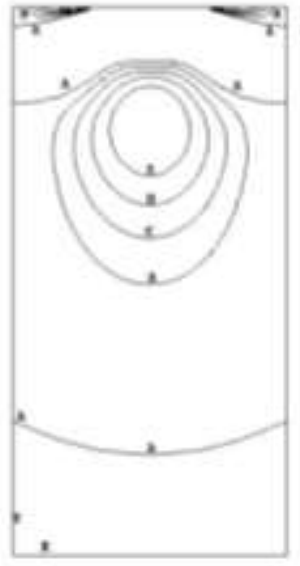

(a) $e_{\text {, }}$

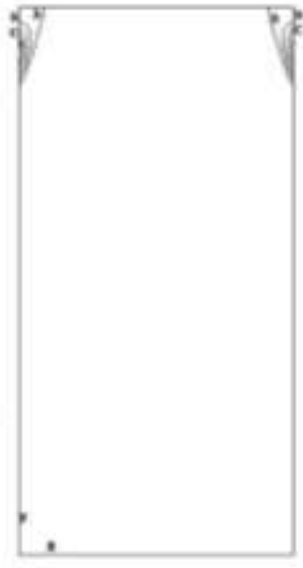

(b)e,

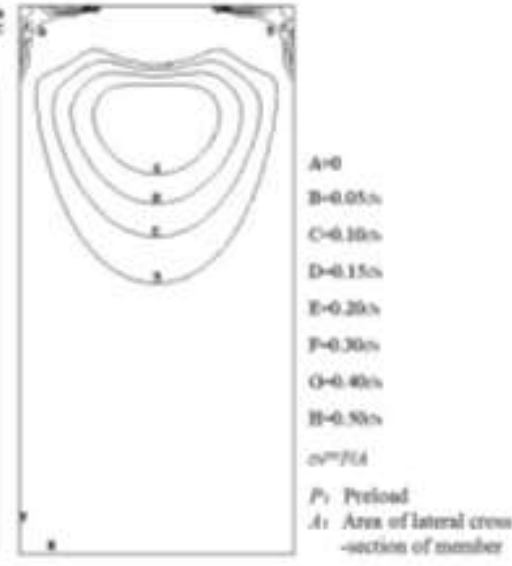

(c) Major principal stress $\sigma_{1}$

Fig. 3 Principal stress vector in centric end anchorage zone with $a / h=0.4$

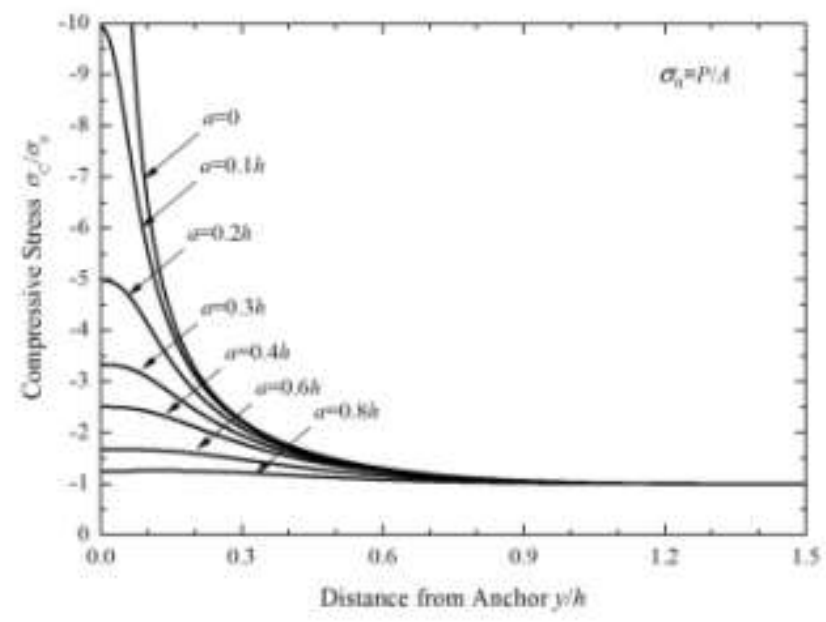

Fig. 4 Compressive stress along the tendon path with various $a / h$

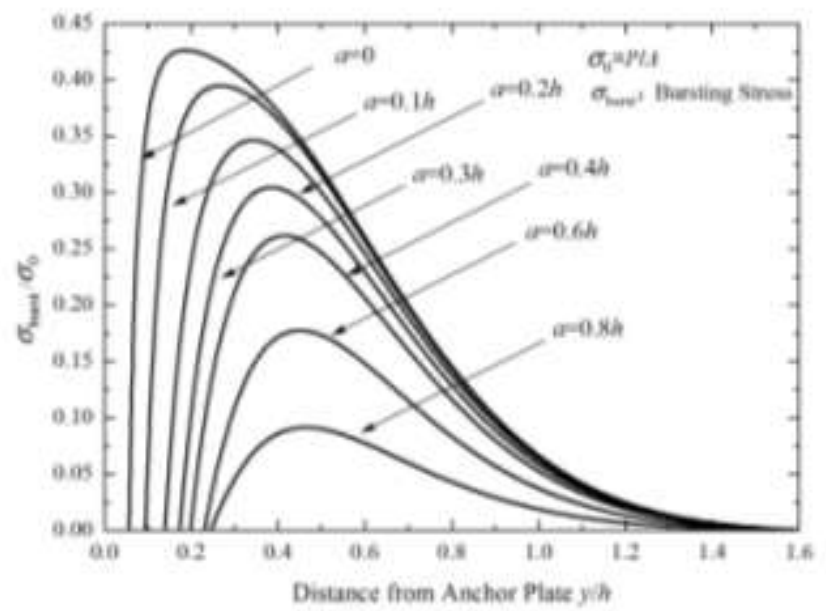

Fig. 5 Bursting stress along the tendon path with various $a / h$ 


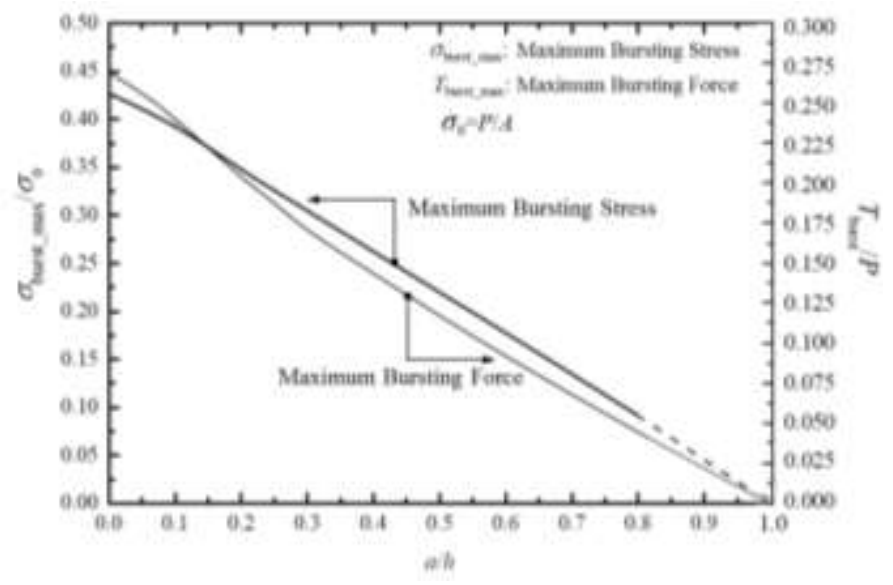

Fig.6 Maximum Bursting Stress and Force as a function of $a / h$

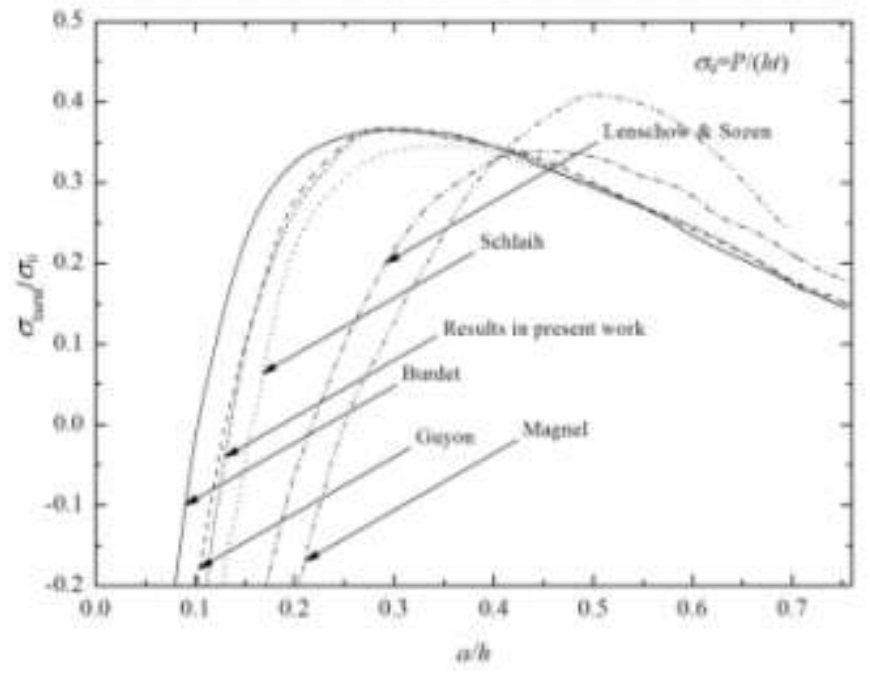

Fig.7 Stress comparison along prestressed tendon at $a / h=0.3$

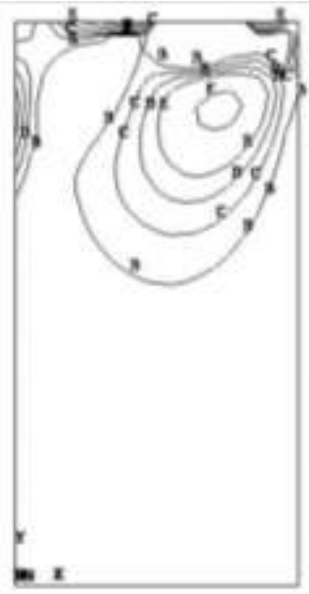

(a) $e h=0.15, a h=0.3$

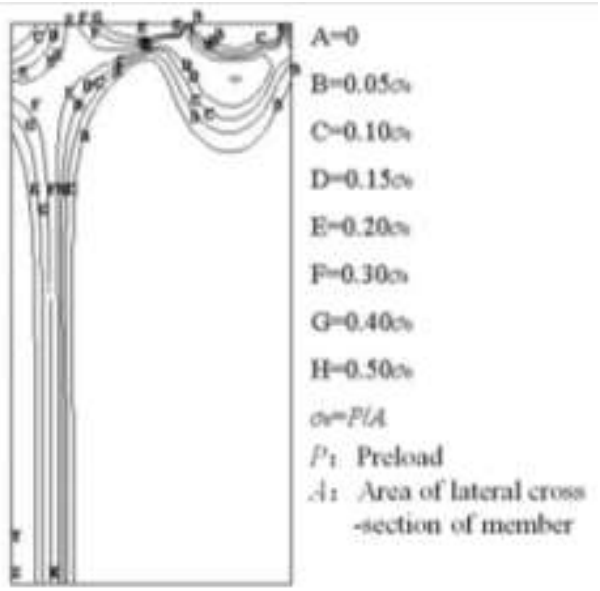

(b) $e h=0,3, a j=0.3$

Fig. 8 Distribution of maximum principle stress in eccentric end anchorage zone with $a / h=0.3$

(a) Small eccentric condition; (b) Large eccentric condition 


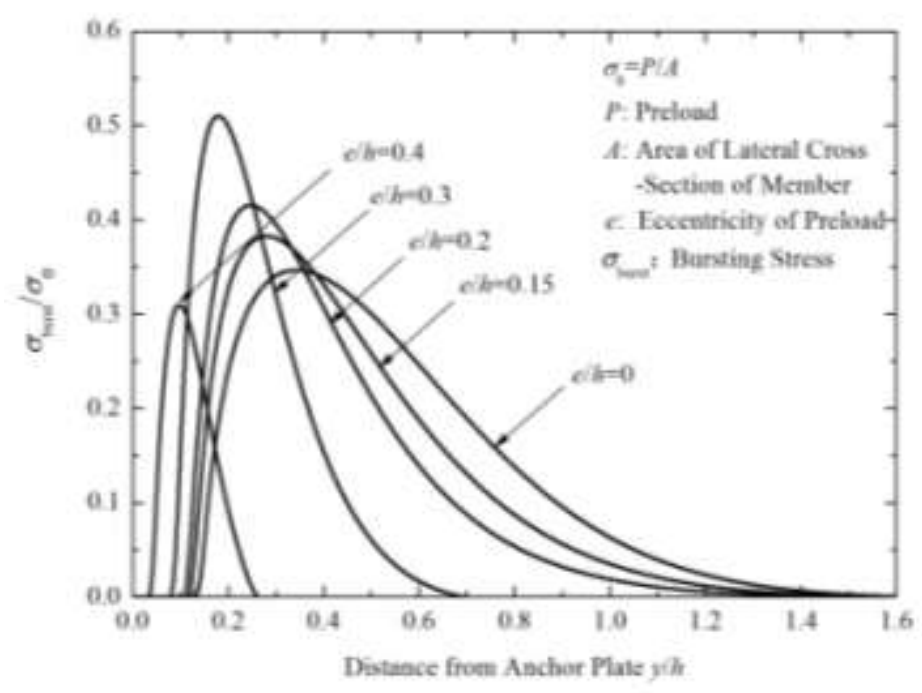

Fig.9 Bursting stress along the tendon path for different $e / h$ with $a / h=0.2$

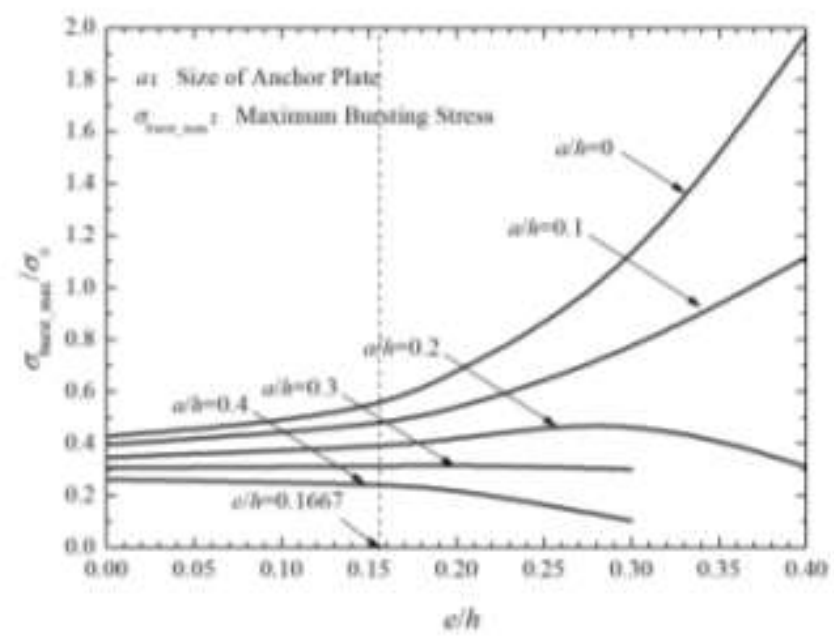

Fig.10 Variation of maximum bursting stress on the tendon path with $e / h$ at every $a / h$

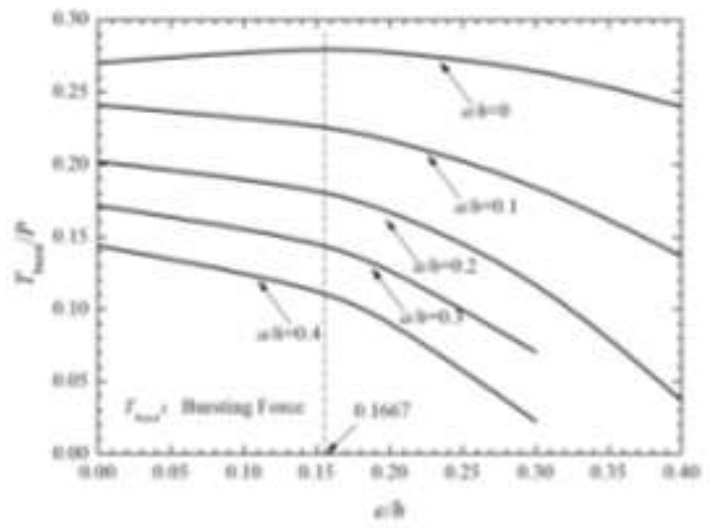

(a)

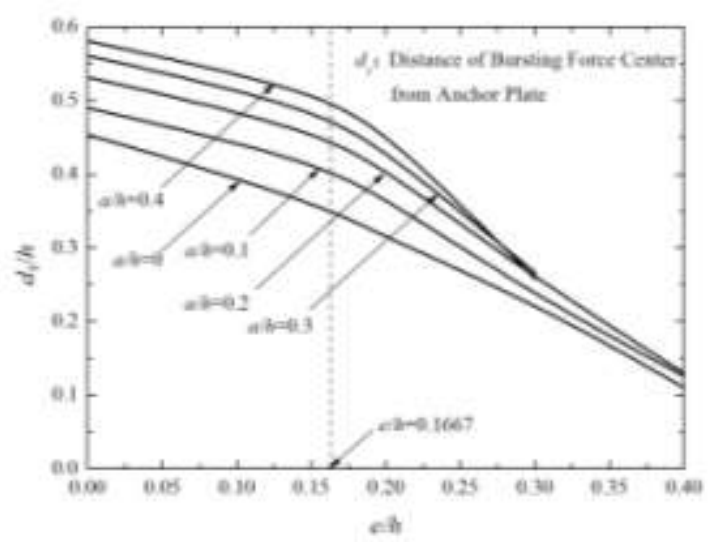

(b) 
Fig.11 Variation of bursting force in values (a) and locations (b) with $e / h$ at various $a / h$

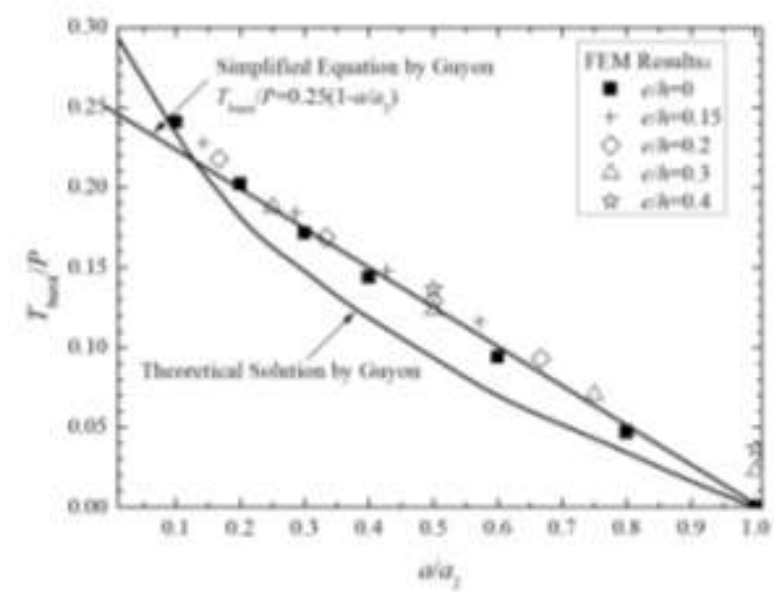

Fig.12 Comparison of bursting force from FEM analysis with Guyon's solution from symmetrical prism method

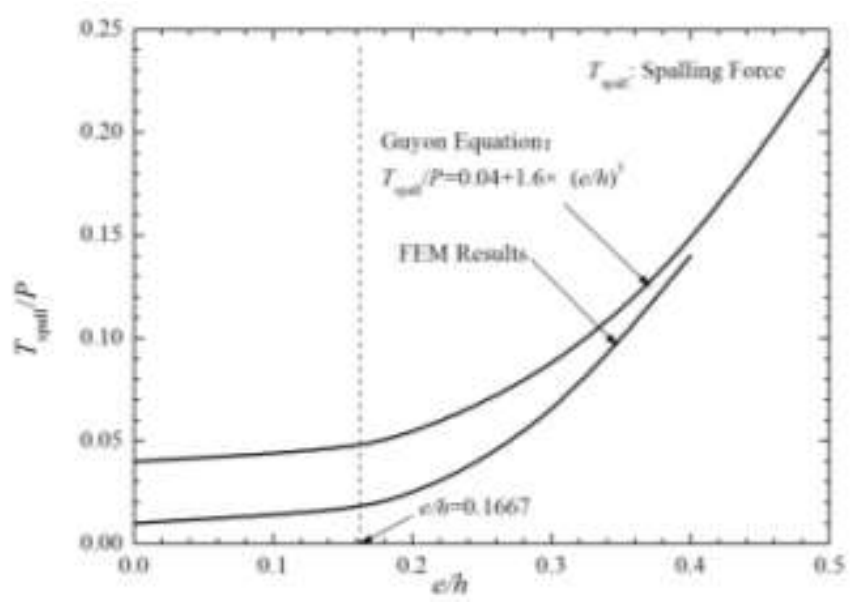

Fig.13 Spalling force as a function of $e / h$

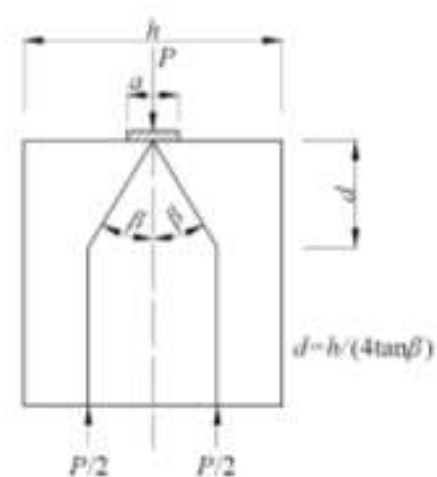

(a)

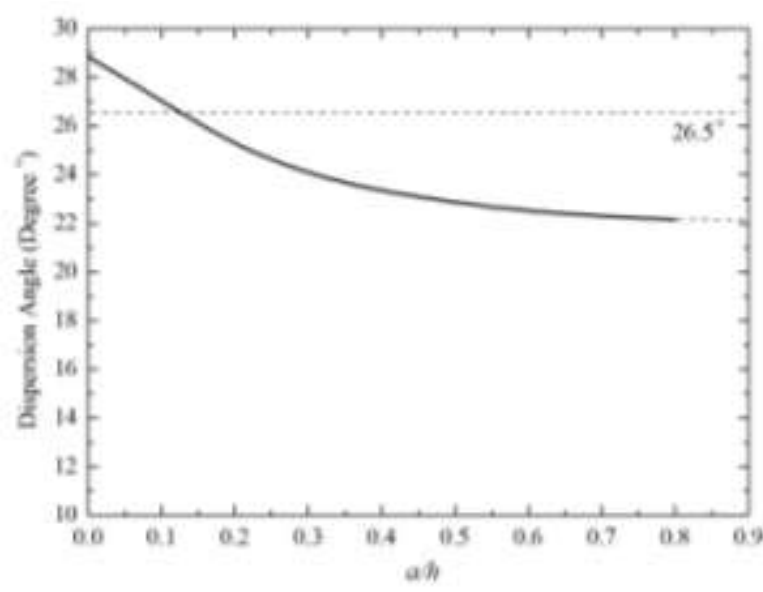

(b)

Fig.14 Dispersion angle 
(a) Definition of dispersion angle; (b) Dispersion angle as a function of $a / h$

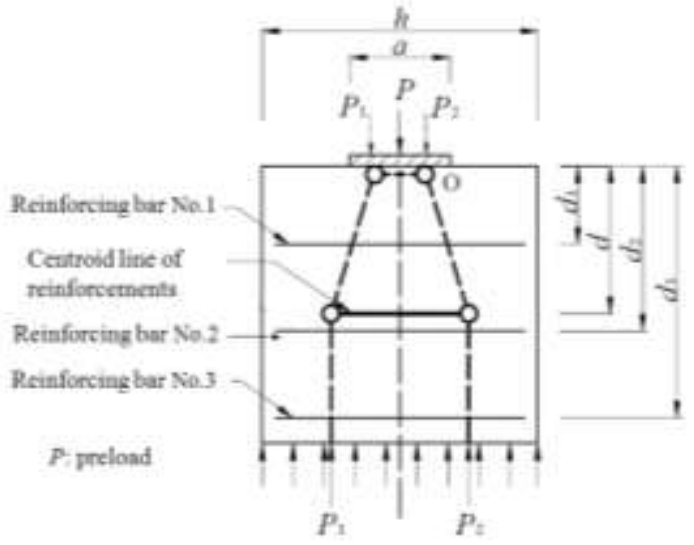

(a)

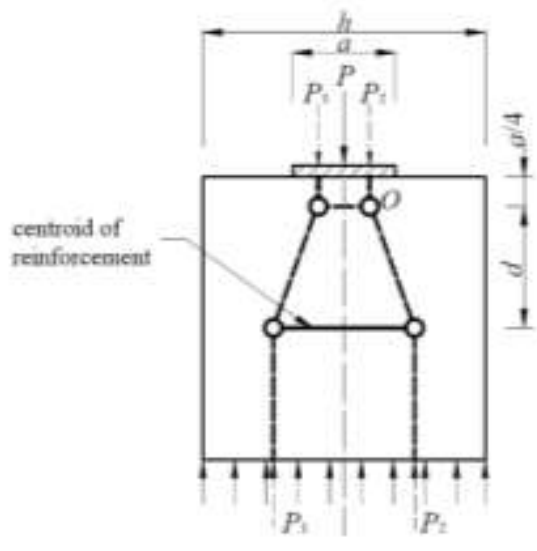

(b)

Fig. 15 Improvement of the Strut-and-tie model for end anchorage zone. (a) STM by Mörsch, (b) Improved STM

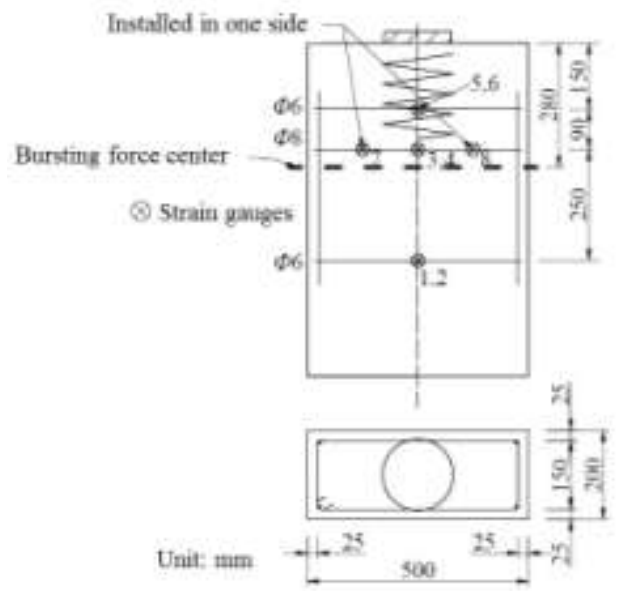

(a)

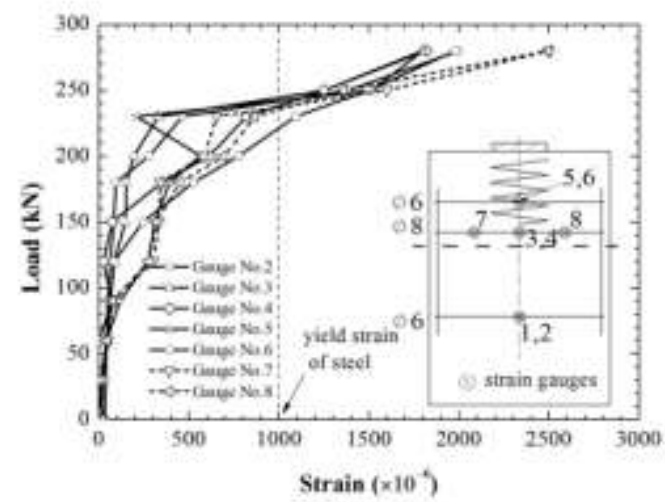

(b)

Fig. 16 Concrete specimen with reinforcements designed by Mörsch STM (a) and lateral strain of reinforcement in concrete specimen during the load (b) 


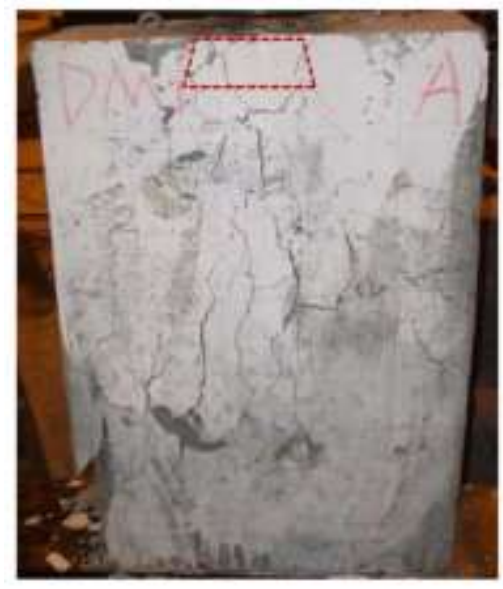

(a)

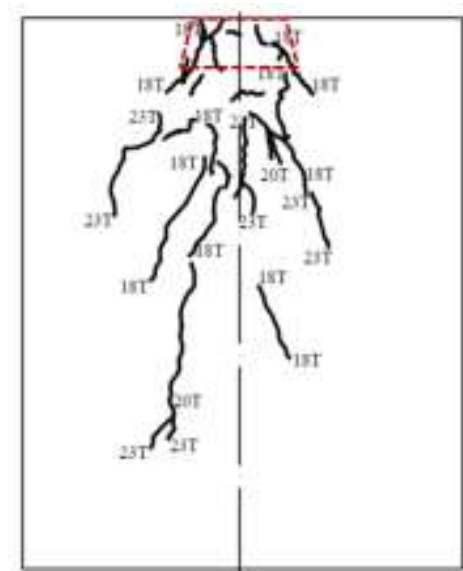

(b)

Fig. 17 Failed concrete specimen (a) and crack distribution in specimen (b)

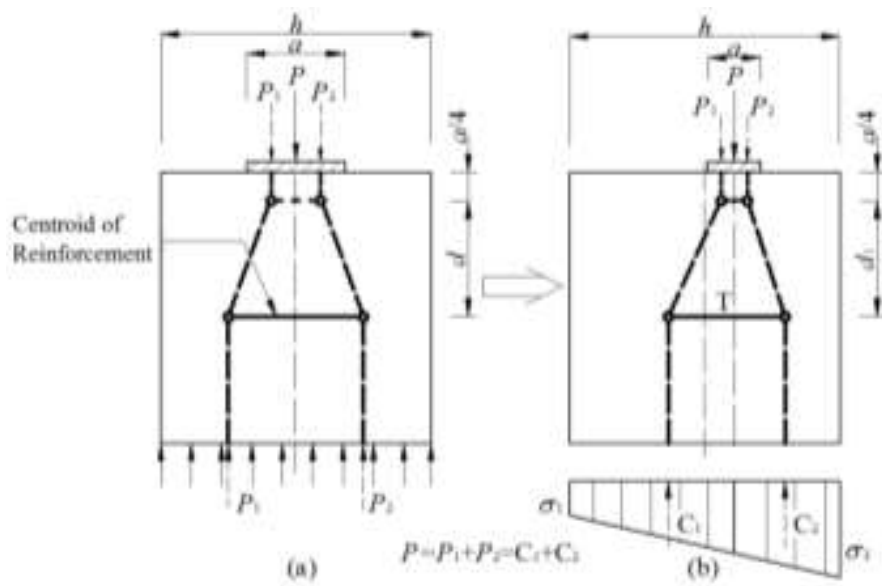

Fig.18 Configuration of STM in small eccentric end anchorage zone

(a) STM for centric end anchorage zone; (b) Adjusted STM for small eccentric end anchorage zone

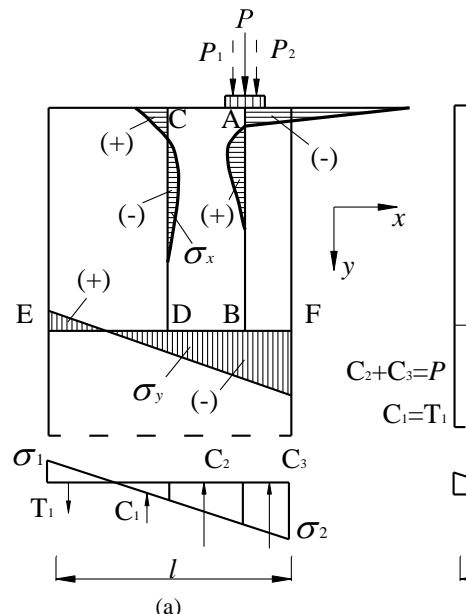

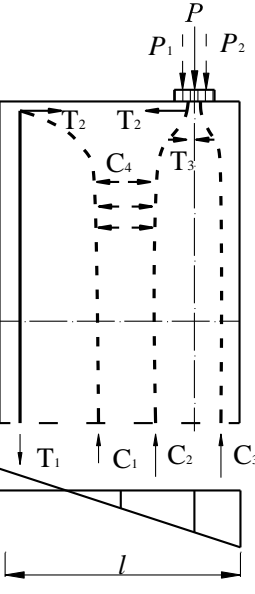

(b)

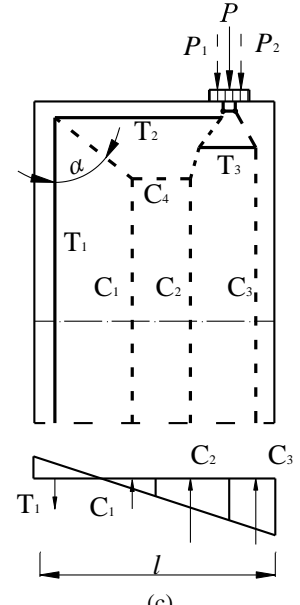

(c)

Fig.19 STM for large eccentric end anchorage zone by Schlaich [23] 


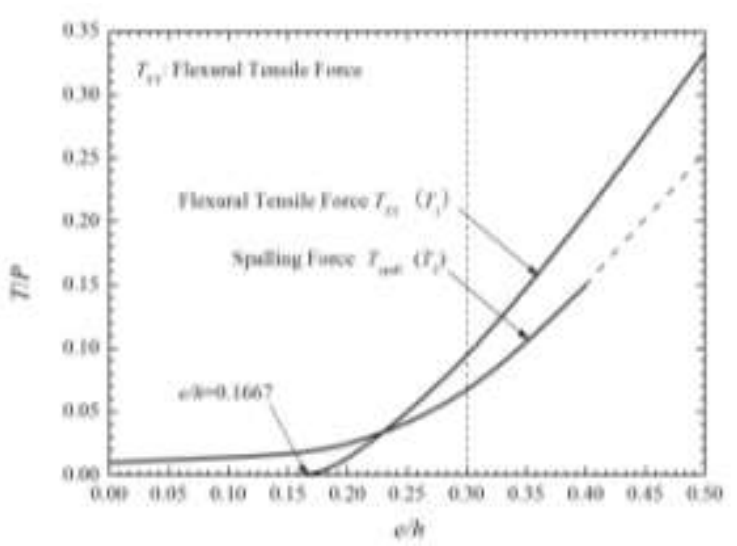

(a)

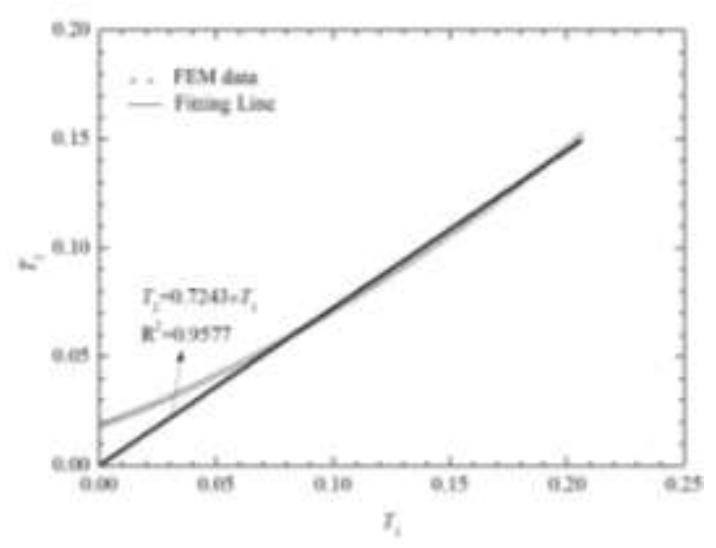

(b)

Fig.20 Determination of Flexural tensile force

(a) $T_{\mathrm{FT}}$ and $T_{\text {spall }}$ as a function of $e / h$; (b) Fitting equation of $T_{2}$

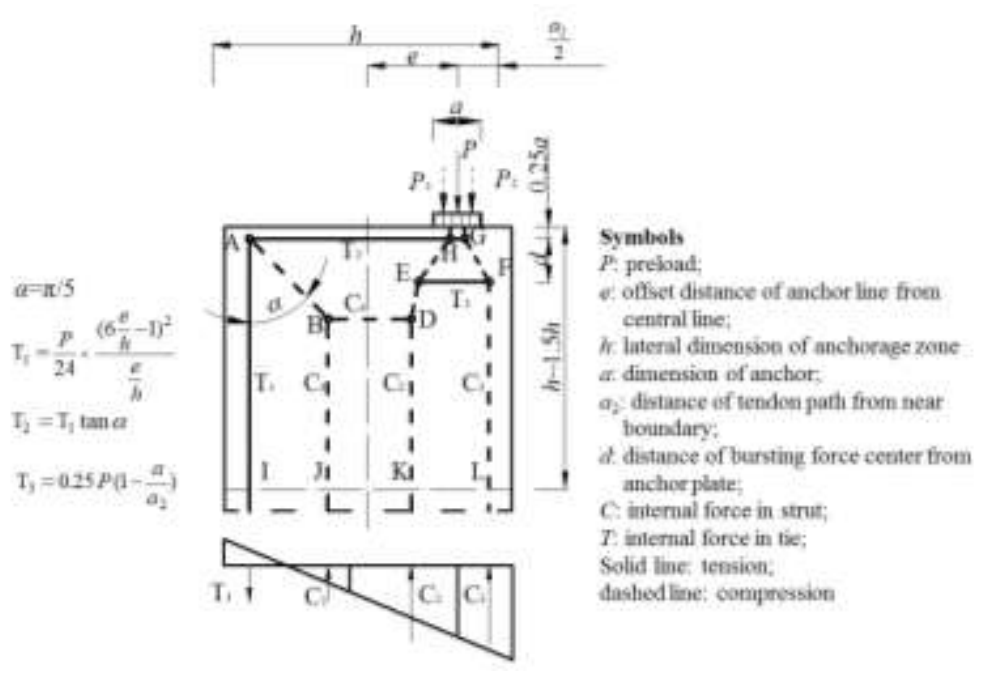

(a)

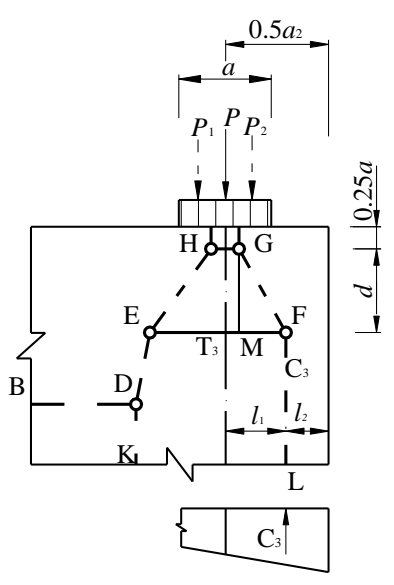

(b)

Fig.21 Improved configuration of Schlaich's STM for large eccentric end anchorage zone (a) and magnifying picture of adjacent zone under anchor plate

Table 1.Parameters in FEM simulations for end anchorage zone

\begin{tabular}{ccrccc}
\hline Model Size & Elements Size & Anchor Size & Load & Elastic Modulus & Poisson's Ratio \\
\hline$h * \times 2 h$ & $<0.02 h$ & $0.1 \sim 0.8 h$ & $200 \mathrm{~N}$ & $32.5 \mathrm{GPa}$ & 0.16 \\
\hline
\end{tabular}

$* h=500 \mathrm{~mm}$ 
Table 2.Combinations of $e / h$ and $a / h$ in FEM simulations for eccentric end anchorage zone

\begin{tabular}{cl}
\hline$e / h$ & \multicolumn{1}{c}{$a / h$} \\
\hline 0 & $0,0.1,0.2, \ldots \ldots, 0.9$ \\
0.15 & $0,0.1,0.2, \ldots \ldots, 0.7$ \\
0.2 & $0,0.1,0.2, \ldots \ldots, 0.6$ \\
0.3 & $0,0.1,0.2,0.3,0.4$ \\
0.4 & $0,0.1,0.2$ \\
\hline
\end{tabular}

\section{Notation List}

$a$ : dimension of anchor plate

$a_{2}$ : distance of tendon path from near boundary;

$A$ :Area of lateral cross -section of member

$b$ : thickness of member

$C_{i}$ : Compression force in struts, $(i=1,2,3,4$. $)$

$d$ : distance of bursting force center from anchor plate;

$d_{i}$ : Distance of Steel Bar No. $i$ from Anchor Plate $(i=1,2,3$.)

$e$ : Eccentric Distance

$h$ : lateral dimension of anchorage zone

$\boldsymbol{P}$ :Preload

$P_{1}, P_{2}$ : Decomposition load of $P$

$\sigma_{0}$ : uniform stress, P/A

$\sigma_{\mathrm{x}}:$ stress in $x$ direction

$\sigma_{\mathrm{y}}:$ stress in $y$ direction

$\sigma_{1}, \sigma_{2}:$ Stress in the side of anchorage zone

$\sigma_{\text {burst }}$ : Bursting stress

$T_{\text {burst }}$ : Bursting force

$\sigma_{\text {spall }}:$ Spalling stress

$T_{\text {spall: }}$ spalling force

$T_{i}$ : Tension force in ties, $(i=1,2,3$. $)$

$M$ : Additional bending moment, $M=P \times e$

$W$ : section moment of anchorage zone

$\sigma_{\mathrm{FT}}$ : flexural-tensile stress

$T_{\mathrm{FT}}$ : flexural-tensile force

$\beta$ : disperse angle 